Peter Inson

\title{
Parents and education and schools
}

Abstract. When compulsory education was first under consideration in Britain in the 19th century, there was much concern about the infringement of parents' rights. T.H. Green, professor of moral philosophy at Oxford, solved this conundrum by claiming that compulsion would be a justifiable intrusion, necessary for only one generation of children. Parents who had themselves been to school would naturally come to appreciate education and desire education for their children. Several generations on, we still await that happy dawn. Now, in the 21st century, there is much new discussion about the nature and purpose of schools: independent, local authority controlled, free schools set up by parents, schools sponsored by other bodies such as religious groups, and academies, often grouped under a sponsoring foundation. Amid all this, however, we should not forget from where our students come-from homes and families — and it is these young people, the students, who are the concern and purpose of schools and of education. I mention both education and school here, deliberately, for we should keep in mind the distinction between the two things. Education may occur in a school, but it can take place elsewhere: in the home, while travelling or while listening to someone-whenever someone is brought to appreciate and understand something for the first time. Schools may well provide opportunities for this to happen, but attending school does not guarantee that it will happen unless a pupil can be brought to engage with teachers there, and with the business of learning. In the UK, the law requires parents to provide an efficient education for their children. It does not require children to attend a school but, for most parents, sending their children to a school is the easiest way to meet this obligation. Behind all this, of course, is the assumption that if children attend school they will be educated. In this article I want to look at parental responsibility more widely, at confusion and uncertainty about our expectations for young people and of young people, and at a better relationship between parents, children and teachers. The article has in mind a greater consistency in our approach to parenting, to young people and to the way children are brought up and educated. It is mainly UK focused.

Nanotechnology Perceptions 13 (2017) 190-202

doi: 10.4024/N21IN17A.ntp.13.03 